\title{
Intravenous infusions of glucose stimulate key lipogenic enzymes in adipose tissue of dairy cows in a dose-dependent manner
}

\author{
Mirja Carra, ${ }^{*}$ Bahaa Al-Trad, ${ }^{*}$ Gregory B. Penner,† Thomas Wittek,‡ Gotthold Gäbel,§ Manfred Fürll,\# \\ and Jörg R. Aschenbachll ${ }^{1}$ \\ *Institute of Physiology, Pathophysiology and Biophysics, University of Veterinary Medicine Vienna, 1210 Vienna, Austria \\ †Animal and Poultry Science, University of Saskatchewan, Saskatoon, Canada, S7N 5A8 \\ $\ddagger$ Clinic for Ruminants, University of Veterinary Medicine Vienna, 1210 Vienna, Austria \\ §Institute of Veterinary Physiology, University of Leipzig, 04103 Leipzig, Germany \\ \#Clinic for Large Animal Internal Medicine, University of Leipzig, 04103 Leipzig, Germany \\ IIInstitute of Veterinary Physiology, Department of Veterinary Medicine, Freie Universität Berlin, 14163 Berlin, Germany
}

\section{ABSTRACT}

The present study was investigated whether increasing amounts of glucose supply have a stimulatory effect on the mRNA abundance and activity of key lipogenic enzymes in adipose tissue of midlactation dairy cows. Twelve Holstein-Friesian dairy cows in midlactation were cannulated in the jugular vein and infused with either a $40 \%$ glucose solution $(n=6)$ or saline $(n=6)$. For glucose infusion cows, the infusion dose increased by $1.25 \% / \mathrm{d}$ relative to the initial net energy for lactation $\left(\mathrm{NE}_{\mathrm{L}}\right)$ requirement until a maximum dose equating to a surplus of $30 \% \mathrm{NE}_{\mathrm{L}}$ was reached on $\mathrm{d} 24$. This maximum dose was maintained until d 28 and stopped thereafter (between d 29-32). Cows in the saline infusion group received an equivalent volume of $0.9 \%$ saline solution. Samples of subcutaneous adipose tissue were taken on d $0,8,16,24$, and 32 when surplus glucose reached 0,10 , 20 , and $30 \%$ of the $\mathrm{NE}_{\mathrm{L}}$ requirement, respectively. The mRNA abundance of fatty acid synthase, cytoplasmic acetyl-coenzyme A synthetase, cytoplasmic glycerol 3-phosphate dehydrogenase-1, and glucose 6-phosphate dehydrogenase showed linear treatment $\times$ dose interactions with increasing mRNA abundance with increasing glucose dose. The increased mRNA abundance was paralleled by a linear treatment $\times$ dose interaction for fatty acid synthase and acetyl-coenzyme A synthetase enzymatic activities. The mRNA abundance of ATPcitrate lyase showed a tendency for linear treatment $x$ dose interaction with increasing mRNA abundance with increasing glucose dose. The mRNA abundance of all tested enzymes, as well as the activities of fatty acid synthase and acetyl-coenzyme A synthetase, correlated with plasma glucose and serum insulin levels. In a multiple regression model, the predictive value of in-

Received October 9, 2012.

Accepted March 24, 2013.

${ }^{1}$ Corresponding author: joerg.aschenbach@fu-berlin.de sulin was dominant over that of glucose. In conclusion, gradual increases in glucose supply upregulate key lipogenic enzymes in adipose tissue of midlactating dairy cows with linear dose dependency. Insulin appears to be critically involved in this regulation.

Key words: adipose tissue, dairy cow, insulin, lipogenic enzyme

\section{INTRODUCTION}

Though the liver is the key organ for lipogenesis in man and most mammals, adipose tissue is the predominant lipogenic site in ruminants (Ingle et al., 1973; Laliotis et al., 2010). A second special feature of ruminants is that little glucose is available for absorption under many dietary regimens, as most of the ingested carbohydrates are fermented by microbes to short-chain FA (e.g., acetate, propionate, and butyrate) in the forestomach (Young, 1977; Reynolds et al., 1994; Aschenbach et al., 2010). As a result, the lipogenic system of ruminant adipose tissue has adapted to use acetate rather than glucose as the major substrate for FA synthesis (Vernon, 1980; Nafikov and Beitz, 2007). Nonetheless, glucose is required to generate the reduced NADPH needed for de novo FA synthesis. Glucose is also the major precursor for glycerol 3-phosphate used to esterify FA to triglycerides (Vernon, 1980; Nafikov and Beitz, 2007). When glucose is supplied in excess of demand, it primarily increases the conversion of acetate into lipid; however, glucose itself can also serve as a quantitatively important precursor of FA synthesis in ruminant adipose tissue under such circumstances (Ballard et al., 1972; Prior and Scott, 1980; Pearce and Piperova, 1984).

Many studies in nonlactating ruminants established that the rate of glucose incorporation into FA and activities of involved enzymes can be increased significantly by increasing the available glucose (Ballard et al., 1972; Prior and Scott, 1980). However, it is not clear whether these results can be extrapolated to lactating ruminants, particularly dairy cows, as glucose requirements 
and glucose distribution may grossly differ between the lactating and the nonlactating state (Aschenbach et al., 2010). Furthermore, studies designed to investigate the effect of surplus glucose on lipogenesis in bovine adipose tissue (Prior and Jacobson, 1979; Prior and Scott, 1980; McLeod et al., 2007) have not included evaluating the dose effects of surplus glucose on the activities and gene expression levels of adipose lipogenic enzymes. Therefore, the first aim of the present study was to investigate the dose effect of an increasing intravenous glucose infusion on mRNA abundance and enzyme activity of the main subcutaneous adipose tissue (SAT) lipogenic enzymes involved in de novo FA synthesis in dairy cows. We considered the gene expressions and activities for FA synthase (FAS; EC 2.3.1.85), an enzyme catalyzing the rate-limiting step in the pathway of FA synthesis de novo in bovine SAT (Smith and Prior, 1986), cytoplasmic acetyl-coenzyme A synthetase (ACS; EC 6.2.1.1) as the rate-limiting enzyme that controls the rate of de novo FA synthesis from acetate (Quraishi and Cook, 1972), and glucose 6-phosphate dehydrogenase (G6PD; EC 1.1.1.49) as an enzyme involved in maintaining reduced NADPH supply for de novo FA synthesis. The gene expression of cytoplasmic glycerol 3-phosphate dehydrogenase-1 (G3PD1; EC 1.1.1.8), an enzyme involved in glycerol 3-phosphate synthesis from glucose being essential in the esterification of the FA, and of ATP-citrate lyase (ACLY; EC 4.1.3.8), an enzyme catalyzing the extramitochondrial cleavage of citrate to oxaloacetate and acetyl-CoA, were also investigated. The latter enzyme is necessary for glucose carbon conversion into FA.

A second aim of the present study was to investigate whether possible changes in mRNA abundance or activities of the above-described enzymes may be related to plasma glucose or insulin levels. This was especially important, as a previous report had questioned the role of insulin for lipogenesis in bovine adipose tissue (Smith et al., 1983).

\section{MATERIALS AND METHODS}

\section{Animals and Experimental Design}

The Regierungspräsidium Leipzig (reference 249168.11, TVV 49/06) approved all experimental procedures for the study. The general experimental design and the production traits during the experiment have been described in detail in an earlier report (Al-Trad et al., 2009). In brief, the experiments were carried out on 12 midlactation Holstein-Friesian cows from the dairy herd of the University of Leipzig. Cows had BW and milk yields (mean $\pm \mathrm{SEM}$ ) of $632 \pm 33 \mathrm{~kg}$ and $25 \pm$ $3 \mathrm{~kg} / \mathrm{d}$, respectively, at the start of the experiment.
Twice daily, cows were offered grass haylage $(60.2 \%$ of total DM) and a concentrate supplement containing a commercial concentrate mix for lactating dairy cows (Multilac; $27.2 \%$ of total DM; Leikra GmbH, Leipzig, Germany) and soybean meal (12.6\% of total DM; Al-Trad et al., 2009). The diet contained 6.72 MJ of $\mathrm{NE}_{\mathrm{L}} / \mathrm{kg}$ of $\mathrm{DM}$ and had the following approximate composition ( $\mathrm{g} / \mathrm{kg}$ of DM); $202.1 \mathrm{CP}, 162.5$ utilizable protein, 33.2 ether extract, 95.4 crude ash, 231.9 ADF, 379.0 NDF, 43.7 sugar, 112.6 starch, $22.1 \mathrm{~K}, 1.0 \mathrm{Na}$, 7.6 Ca, 5.0 P, and 2.4 Mg. Water was available for ad libitum intake. Cows were milked twice daily at 0630 and $1600 \mathrm{~h}$. Cows were allocated randomly to continuous intravenous glucose infusions $(\mathbf{G I} ; \mathrm{n}=6)$ or saline infusions ( $\mathbf{S I} ; \mathrm{n}=6$ ) over $24 \mathrm{~h}$. The GI consisted of continuous jugular infusions of $40 \%$ glucose solution (40\% Glukoselösung, Serumwerk Bernburg, Bernburg, Germany) over a period of $28 \mathrm{~d}$. The infusion dose was calculated for each animal separately as a percentage of daily $\mathrm{NE}_{\mathrm{L}}$ requirements for maintenance and lactation according to NRC (2001). Net energy required for maintenance and lactation $(\mathrm{MJ} / \mathrm{d})$ was calculated as $4.184 \times\left\{\mathrm{BW}^{0.75} \times 0.08+\right.$ milk yield $(\mathrm{kg}) \times[(0.0929$ $\times$ fat $\%)+(0.0563 \times$ protein $\%)+(0.0395 \times$ lactose $\%)]\}$ according to the NRC (2001). The infusion dose (kg of glucose/d) was calculated as designated dose level $\times \mathrm{NE}_{\mathrm{L}} /(15.6 \mathrm{MJ} / \mathrm{kg})$. The infusion dose increased linearly by $1.25 \%$ each day until a maximum dose of $30 \%$ of the $\mathrm{NE}_{\mathrm{L}}$ requirement was reached at $\mathrm{d} 24$. This maximum dose (equal to $2.65 \pm 0.19 \mathrm{~kg}$ of glucose per cow per day) was maintained until d 28 (i.e., for $4 \mathrm{~d}$ ) and stopped thereafter (between d 29-32). The infusion protocol and the individual calculation of infusion volumes were identical in the SI group, except that the latter group received an equal volume of $0.9 \%$ SI $(0.9 \%$ Natriumchloridlösung, Serumwerk Bernburg, Bernburg, Germany) as a control treatment.

Cows used in this study had daily mean plasma glucose and insulin concentrations that showed linear treatment $\times$ dose interactions between d 0 and 24 based on increases in plasma glucose $(3.78-5.49 \mathrm{mM}$; pooled SEM $=0.17 \mathrm{mM}$ ) and insulin concentrations (73-885 $\mathrm{p} M$; pooled SEM $\pm 231 \mathrm{p} M$ ) exclusively in the GI group (Al-Trad et al., 2009). Over the infusion period, from d 0 to 24 , neither daily DMI nor milk production were affected by the treatments; whereas, significant linear increases in the BW, back fat thickness, and energy balance were observed in GI cows (AlTrad et al., 2009).

\section{Sampling and Measurements}

On d $0,8,16,24$, and 32, when surplus glucose reached $0,10,20,30$, and $0 \%$ of the $\mathrm{NE}_{\mathrm{L}}$ requirement, 
SAT samples were taken alternating from the left or right side in the area between the tuber ischiadicum and tuber coxae ( $\sim 3$ g per biopsy) as described by Lake et al. (2007). Following collection, samples were washed immediately in ice-cold $0.9 \%$ saline solution. Sample aliquots for enzyme activity determinations $(\sim 1 \mathrm{~g})$ were snap-frozen in liquid nitrogen and stored at $-80^{\circ} \mathrm{C}$ until further analysis. Samples $(\sim 300 \mathrm{mg})$ for real-time reverse transcription-PCR (rt-PCR) were transferred into tubes with $3 \mathrm{~mL}$ of RNAlater (Qiagen, Germantown, MD), placed in a refrigerator for $24 \mathrm{~h}$, and stored at $-20^{\circ} \mathrm{C}$ thereafter.

\section{Lipogenic Enzyme Activity}

Approximately $0.5 \mathrm{~g}$ of frozen SAT samples were homogenized using Ultra-Turrax T25 homogenizer (IKA, Staufen, Germany) in 1:10 (wt/vol) of ice-cold homogenization buffer (containing $30 \mathrm{~m} M$ of Tris- $\mathrm{HCl}$, $300 \mathrm{~m} M$ of sucrose, $1 \mathrm{~m} M$ of EDTA, and $1 \mathrm{~m} M$ of glutathione; $\mathrm{pH}$ 7.4). The homogenate was centrifuged at $40,000 \times g$ for $45 \mathrm{~min}$ at $4^{\circ} \mathrm{C}$ and the resulting supernatant was used to determine FAS, G6PD, and ACS activities.

The enzyme activities of FAS and ACS were determined using modifications of the previously described radiochemical assays of $\mathrm{Lu}$ and Archer (2007) and $\mathrm{Lu}-$ ong et al. (2000), respectively. The FAS assays were conducted in a final volume of $0.2 \mathrm{~mL}$ at $39^{\circ} \mathrm{C}$ for 30 min, in the presence of $100 \mathrm{~m} M$ of potassium phosphate ( $\mathrm{pH} 6.8$ ), $0.5 \mathrm{~m} M$ of NADPH, $1 \mathrm{~m} M$ of dithiothreitol, $0.05 \mathrm{~m} M$ of acetyl-CoA, $0.05 \mathrm{~m} M$ of malonyl-CoA, and $555 \mathrm{~Bq}$ of $\left[{ }^{14} \mathrm{C}\right]$ malonyl-CoA. Reactions were terminated by the addition of $1 \mathrm{~mL}$ of ice-cold $1 \mathrm{~N} \mathrm{HCl} /$ methanol $(6: 4, \mathrm{vol} / \mathrm{vol})$ and the FA were extracted with $1 \mathrm{~mL}$ of petroleum ether. Following centrifugation at 5,000 $\times g$ for $5 \mathrm{~min}$ at room temperature, the incorporation of radioactivity into the FA was assessed in the upper phase by a liquid scintillation counter (Tri-Carb 2100TR, Perkin Elmer, Waltham, MA). Results were corrected for blanks where NADPH was omitted from the reaction mixture.

Each reaction mixture for ACS assays contained the following components in a final volume of $0.25 \mathrm{~mL}$ : 60 $\mathrm{m} M$ of potassium phosphate $(\mathrm{pH} 7.5), 3 \mathrm{~m} M$ of ATP, $0.1 \mathrm{~m} M$ of CoA, $4 \mathrm{~m} M$ of $\mathrm{MgCl}_{2}, 1 \mathrm{~m} M$ of Dithiothreitol, $0.24 \mathrm{~m} M$ of sodium acetate, and $555 \mathrm{~Bq}$ of sodium $\left[{ }^{14} \mathrm{C}\right]$ acetate. Reactions were incubated at $39^{\circ} \mathrm{C}$ for 30 min, after which the reaction was stopped by adding $100 \mu \mathrm{L}$ of ice-cold $20 \%$ (wt/vol) trichloroacetic acid. Thereafter, a $20-\mu \mathrm{L}$ aliquot of the reaction mixture was spotted onto Whatman qualitative filter papers (Whatman International Ltd., Maidstone, UK), washed 2 times with 7:1 ether-formic acid, and air-dried. The amount of $\left.{ }^{14} \mathrm{C}\right]$ acetyl-CoA formed was determined by counting the washed papers in a scintillation counter (Tri-Carb 2100TR). Blank readings were generated by omitting CoA from the reaction mixture.

Glucose 6-phosphate dehydrogenase catalytic activity was assayed photometrically (U-2000 UV/Vis Spectrophotometer, Hitachi High Technologies America Inc., Pleasanton, CA) at $39^{\circ} \mathrm{C}$ by measuring the $\mathrm{NADP}^{+}$to NADPH ratio during catalytic conversion of glucose 6-phosphate to 6-phosphogluconolactone at $340 \mathrm{~nm}$ (Chilliard et al., 1991).

\section{RNA Isolation and Quantitative rt-PCR Analysis}

An automated RNA purification protocol from SAT stored in RNAlater was carried out on the QIAcube instrument (Qiagen, Hilden, Germany) using the RNeasy Lipid Tissue Mini Kit (Qiagen) according to the manufacturer's instructions. The quality of RNA was assessed using the Agilent 2100 Bioanalyzer (Agilent Technologies GmbH, Vienna, Austria). Samples had an average RNA integrity value of 6.9. Total RNA (100 ng) was reverse transcribed using random primers in a $20-\mu \mathrm{L}$ reaction of the High-Capacity cDNA Reverse Transcription Kit (Applied Biosystems, Foster City, CA) according to the manufacturer's instructions. Reverse transcription reactions were carried out on a StepOnePlus (Agilent Technologies $\mathrm{GmbH}$ ) at $25^{\circ} \mathrm{C}$ for $10 \mathrm{~min}$ followed by $37^{\circ} \mathrm{C}$ for $120 \mathrm{~min}$ and $85^{\circ} \mathrm{C}$ for $5 \mathrm{~min}$. The resulting first-strand cDNA was stored at $-80^{\circ} \mathrm{C}$ until use for rt-PCR. Beta-2 microglobulin (B2M) was used as nonregulated reference gene.

Polymerase chain reaction primers and dual-labeled fluorescent probes (Table 1) were designed using the web-based real-time PCR primer design software provided by Genscript Inc. (Piscataway, NJ; http://www. genscript.com) and synthesized by MWG Biotech AG (Ebersberg, Germany). For each sample, the target gene and the control gene were run under duplex reaction conditions in duplicate using Rotor-Gene Multiplex PCR Kit (Qiagen) on a Rotor-Gene 6000 (Qiagen) with 72 tubes per rotor. The following reagents were used for amplification in $10 \mu \mathrm{L}$ of final volume: $1 \mu \mathrm{L}$ of sample cDNA, $5 \mu \mathrm{L}$ of Rotor-Gene Multiplex PCR Master Mix (Qiagen), $500 \mathrm{nmol}$ of each primer, and $200 \mathrm{nmol}$ of each probe for the genes of interests and B2M. Amplification conditions for quantification were $95^{\circ} \mathrm{C}$ for $5 \mathrm{~min}$ and 40 cycles of $95^{\circ} \mathrm{C}$ for $20 \mathrm{~s}$ and $60^{\circ} \mathrm{C}$ for $20 \mathrm{~s}$. After the amplification efficiency of each target and reference gene was validated, the relative gene expression levels were determined by the $2^{-\Delta \Delta \mathrm{CT}}$ method as described previously (Livak and Schmittgen, 2001). Gene expression was expressed as the normalized ratio of gene expression relative to B2M mRNA. A pooled 
Table 1. Sequences of primers and probes used for quantitative real-time reverse transcription-PCR

\begin{tabular}{|c|c|c|c|}
\hline Gene $^{1}$ & $\begin{array}{l}\text { GenBank } \\
\text { accession }\end{array}$ & $\begin{array}{l}\text { Nucleotide } \\
\text { range }\end{array}$ & Primer and probe sequence ${ }^{2}$ \\
\hline \multirow{2}{*}{ B2M } & BC118352.1 & $102-123$ & Forward: 5'-AGCGTCCTCCAAAGATTCAAGT-3' \\
\hline & & $137-168$ & Probe: 5'-FAM-CACCAGAAGATGGAAAGCCAAATTACCTGAA-BHQ1-3' \\
\hline \multirow[t]{3}{*}{ FAS } & AY343889.1 & $741-760$ & Forward: 5'-ATCAGGGAATGGCTACTGCC-3' \\
\hline & & $787-811$ & Probe: 5'-CY5-CTGACCAAGAAGTCCCTGGCCCGAC-BHQ2-3' \\
\hline & & $815-834$ & Reverse: 5'-GTTGAGGATGGTGGCGTACA-3' \\
\hline \multirow{3}{*}{ G3PD1 } & BC105513.1 & $442-462$ & Forward: 5'-CAACGAGGTGGCTGATGAGAA-3' \\
\hline & & $474-503$ & Probe: 5'-ROX-CAACCATTGGTAGCAAGAACCAGGCTCATG-BHQ2-3' \\
\hline & & $533-552$ & Reverse: 5'-ACCGTGATGCGGAAATTGGG-3' \\
\hline \multirow{3}{*}{$G 6 P D$} & AY862878.1 & $121-141$ & Forward: 5'-GAGCCCTTCTTCAAAGCTACC-3' \\
\hline & & $178-200$ & Probe: 5'-ROX-CGCAACTCCTACGTGGCCGGCCA-BHQ2-3' \\
\hline & & $204-223$ & Reverse: 5'-TGTAGGAGGCAGTGTCATCG-3' \\
\hline
\end{tabular}

${ }^{1} B 2 M=\beta_{2}$ microglobulin; $F A S=$ FA synthase; $A C S=$ cytoplasmic acetyl CoA synthetase; G3PD1 = cytoplasmic glycerol 3-phosphate dehydrogenase 1; G6PD = glucose 6-phosphate dehydrogenase; $A C L Y=$ ATP-citrate lyase.

${ }^{2} \mathrm{FAM}=6$-carboxyfluorescein; TAMRA $=6$-carboxytetramethylrhodamine; JOE $=2,7$-dimethoxy-4,5-dichloro-6-carboxyfluorescein; $\mathrm{ROX}=$ 6-carboxy-X-rhodamine; $\mathrm{BHQ}=$ blackhole quencher.

sample from d 0, containing equal volumes from 1 animal of the SI and 1 animal of the GI group, was used as an interplate calibrator.

\section{Calculations and Statistical Analysis}

Statistical analyses of data were performed using the PROC MIXED procedure of SAS (SAS, 2002) accounting for repeated measures. The model for analyses of treatment and dose effects during increasing glucose infusions (d 0-24) included the fixed effects of treatment (GI vs. SI), dose (representing dose levels of 0,10 , 20 , and $30 \% \mathrm{NE}_{\mathrm{L}}$ requirement), and their interaction. The $\mathrm{NE}_{\mathrm{L}}$ calculated before the start of the experiment was used as a covariate. In addition, because cows were gradually exposed to increasing dose levels, dose was included in the model as a repeated measure. The covariate error structure that yielded the lowest Akaike's and Bayesian information criterion values for each dependent variable was used. When significant treatment $\times$ day interactions were detected, means were separated using a Bonferroni mean separation test. To determine the effect of infusate dose over time, the linear and quadratic effects of dose and their interaction with treatment were tested. The model included the fixed effect of treatment (GI vs. SI) and the $\mathrm{NE}_{\mathrm{L}}$ calculated before the start of the experiment was used as a covariate. For this analysis, dose was considered to be a continuous variable. Comparisons of postinfusion samples (d 32) to preinfusion samples (d 0) were performed using a Student's paired $t$-test.
Linear and multiple linear correlation coefficients, as well as the linear regression parameters (intercept and slope), their error terms (SE), and the predictive value of multiple regression variables, were estimated using the software Sigma Plot 11 (Systat Software GmbH, Erkrath, Germany). Only values determined during the infusion period (d 0-24; 4 values per cow) were used for the correlation and regression analyses of plasma glucose and serum insulin concentrations with each other and with the mRNA abundance and activity of lipogenic enzymes. Plasma glucose and serum insulin concentrations were derived from Al-Trad et al. (2009; see also footnote 1 to Table 3 ). Differences were considered significant when $P<0.05$. Trends are discussed when $P<0.10$.

\section{RESULTS}

Lipogenic enzyme activities and relative mRNA abundances are listed in Table 2. The relative mRNA abundance of FAS showed a treatment effect $(P<0.05)$, linear dose effect $(P<0.05)$, and linear treatment $\times$ dose interaction $(P<0.01)$ based on an increase in FAS mRNA abundance in the GI group with increasing glucose dose but no change over time for the SI treatment. The increased abundance of FAS mRNA in the GI group corresponded with an increase in FAS activity (linear treatment $\times$ dose interaction; $P<0.01$ ). The relative mRNA abundance of the cytoplasmic ACS also showed a linear dose effect $(P<0.05)$ with a linear treatment $\times$ dose interaction $(P<0.05)$, which cor- 
responded to linear and quadratic treatment $\times$ dose interactions $(P<0.05)$ for ACS activity. Interactions resulted from a dose-dependent, selective increase in mRNA abundance of ACS that was paralleled by a numerical increase in ACS activity in the GI group only.

Cytoplasmic G3PD1 mRNA abundance was greater for GI than SI (treatment effect; $P<0.05$ ) with a linear treatment $\times$ dose interaction $(P<0.05)$. The interaction was based on a numerical increase in G3PD1 mRNA abundance in the GI group with increasing glucose dose; whereas G3PD1 mRNA abundance of the SI group showed a numerical decrease over time.

Treatment affected G6PD mRNA abundance $(P<$ $0.05)$, with a linear dose effect $(P<0.05)$ and linear treatment $\times$ dose interaction $(P<0.01)$. The latter was, again, based on increases in G6PD mRNA abundance in the GI but not the SI group. However, the activity of G6PD was not affected by treatment, dose, or their interactions. The mRNA abundance of ACLY showed tendencies for a treatment effect, linear and quadratic dose effects, and linear and quadratic treatment $\times$ dose interactions $(P<0.10)$; this was based on a $\sim 20$-fold numerical increase in ACLY mRNA abundance in the GI group at the highest infused glucose dose compared with a numerical decrease in the SI group.

Except for G3PD1, abundances of mRNA were higher (FAS, G6PD, ACLY; all $P<0.05$ ) or tended to be higher (ACS; $P=0.087$ ) on d 32 compared with preinfusion values $(\mathrm{d} 0)$ in the GI group only (Table 2 ). For FAS and ACS, this tended to coincide $(P=0.058)$ or coincided $(P<0.01)$ with increased activity in the GI group $4 \mathrm{~d}$ after the end of infusion (d 32) compared with preinfusion values (d 0$)$.

To elucidate whether the observed changes in mRNA abundance and activities might be related to the availability of glucose or insulin in the blood, simple linear correlation and regression analyses were performed. Serum insulin concentration was positively correlated with the mRNA abundances of all tested enzymes, as well as with the activities of FAS and ACS $(P<0.01$; Table 3$)$. The $\mathrm{R}^{2}$-value for these correlations varied between 0.20 and 0.42 . Only G6PD activity was not correlated to serum insulin, having a slope not different from zero. With the exception of ACLY, all regressions had an intercept that was $(P<0.05)$ or tended (ACS mRNA only; $P=0.052$; Table 3 ) to be different from zero.

Serum insulin concentration itself was related to plasma glucose concentration $\left(\mathrm{R}^{2}=0.58 ; P<0.001\right.$; Table 3$)$. The respective regression had a significant but negative intercept $(P<0.001$; Table 3$)$. Negative intercepts were also observed for regression between plasma glucose concentration and the mRNA abundance of FAS, ACS, G6PD, and ACLY $(P<0.05)$ and, as a trend, for FAS activity $(P=0.055$; Table 3$)$. Furthermore, all measured mRNA abundances, as well as FAS and ACS activities, correlated with plasma glucose concentrations $(P<0.01)$, albeit their correlation coefficients were in all instances numerically smaller than those calculated for the relationships with insulin (Table 3).

Multiple linear regression analysis with the combined parameters plasma glucose and serum insulin also revealed correlations for all mRNA abundances tested, as well as for FAS and ACS activities $(P<0.005$; Table $3)$. The serum concentration of insulin was suitable to predict the mRNA abundances of ACS, G6PD1 and ACLY $(P<0.05)$, and tended to be suitable to predict the mRNA abundance of FAS $(P=0.055)$, as well as the activities of FAS $(P=0.053)$ and ACS $(P=0.087)$. By contrast, plasma glucose concentration was not predictive for any of the measured mRNA abundances or enzyme activities in this combined regression approach (Table 3). None of the regressions had an intercept different from zero.

\section{DISCUSSION}

Consistent with the nutritional strategy, ruminant adipose tissue uses acetate originating from ruminal fermentation rather than glucose as the major substrate for lipid synthesis (Vernon, 1980; Nafikov and Beitz, 2007). The minor role of glucose as a precursor for lipogenesis in ruminant adipose tissue is reflected by a low activity of enzymes of the citrate-cleavage pathway (e.g., ACLY) that are involved in the conversion of glucose to acetyl-CoA (Bauman, 1976; Laliotis et al., 2010). Nonetheless, glucose incorporation into FA can be enhanced substantially by postruminal or intravenous glucose infusions (Bauman, 1976). In a previous study, we had observed marked increases in back fat thickness and BW during increasing intravenous glucose infusion (Al-Trad et al., 2009). As milk performance was completely unaffected by surplus glucose supply, we concluded that midlactation dairy cows on an energy-balanced diet directed any surplus of glucose predominantly to body fat reserves and not to increased lactation performance (Al-Trad et al., 2009). Total lipid content of the liver was also not affected (Al-Trad et al., 2010a), which supports the hypothesis that adipose tissue is the key player in lipogenesis during excessive glucose infusions. However, it remained unknown whether increased lipogenesis was simply the result of increased substrate availability or whether the enzymatic capacity of the lipogenic pathway increased in parallel. Therefore, the present study was specifically designed to evaluate the effects of increasing glucose supply on key lipogenic enzymes in the adipose tissue 
CARRA ET AL.

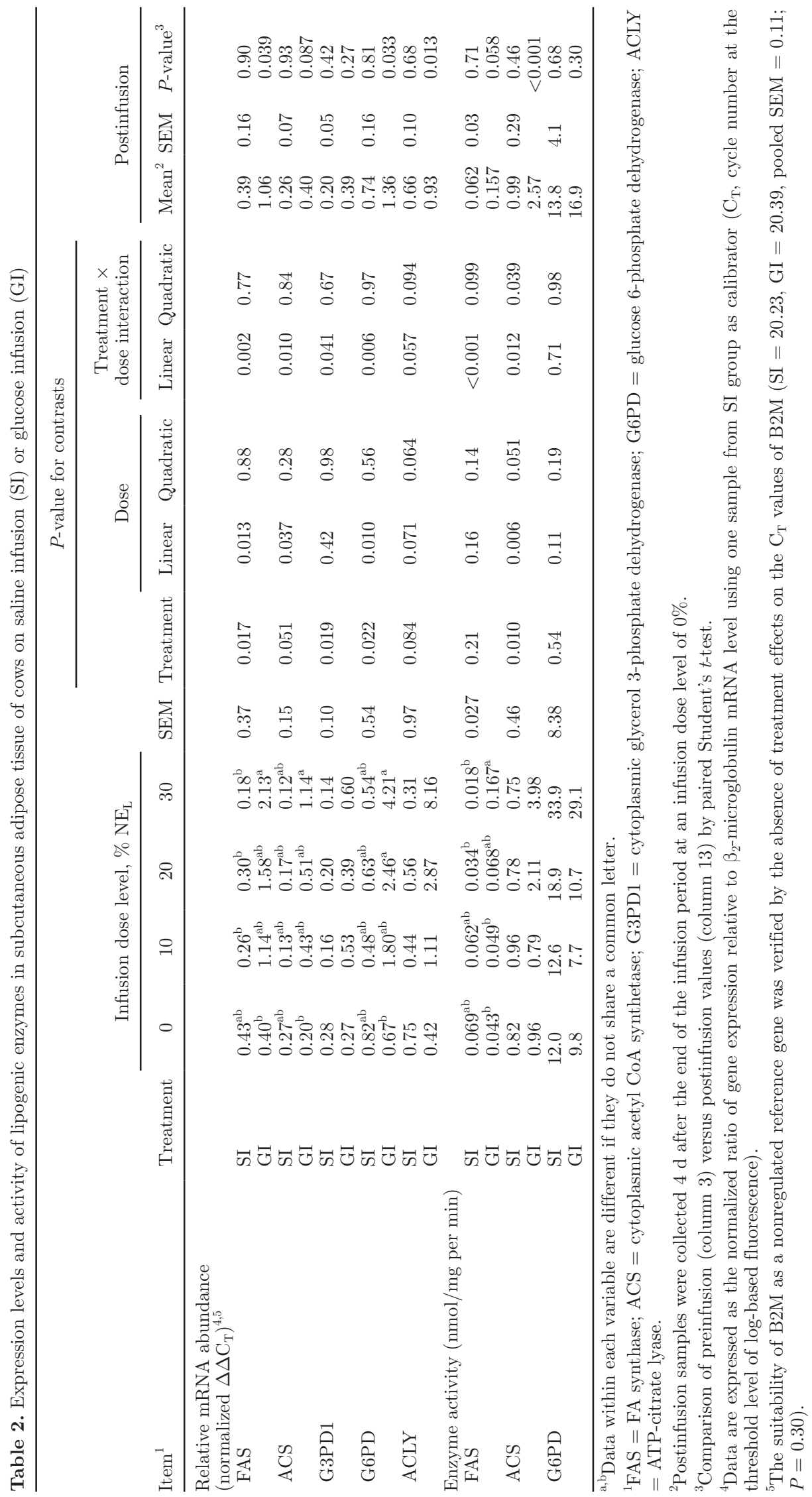




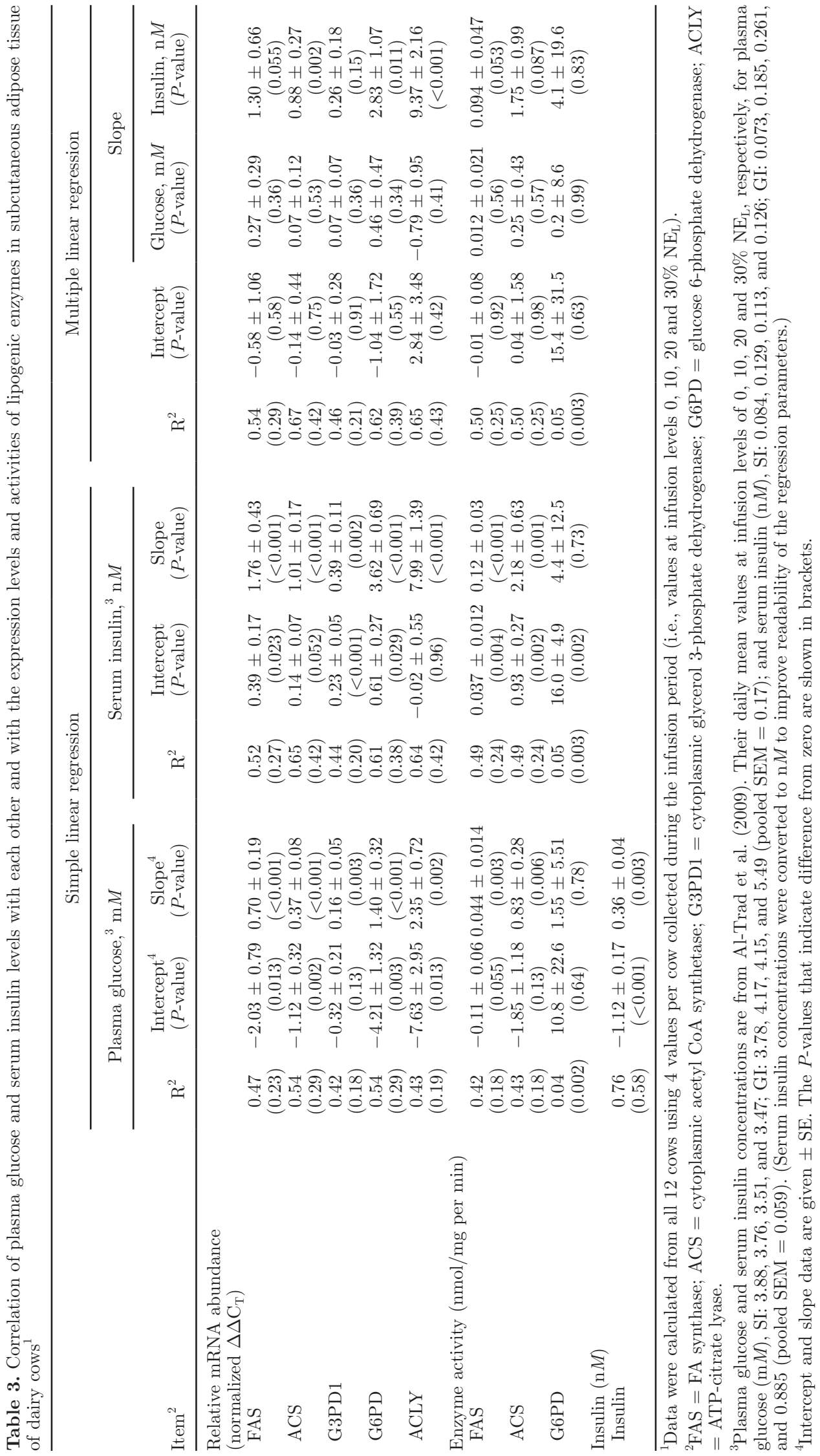


of midlactating dairy cows. The intention was to explore the whole range of nutritionally relevant surplus glucose (Al-Trad et al., 2010b). The infusion protocol was specifically designed to not interfere with daily feed intake. Thus, the samples obtained and used for the present study were from animals consuming constant ad libitum levels of feed on which a defined dose of glucose was added as surplus energy (Al-Trad et al., 2009). Activities of FAS, ACS, and G6PD were measured in the current study simultaneously with their mRNA abundance in response to gradual shifts from a slightly negative energy balance at the beginning of the experiment into a strong positive energy balance when infusing glucose at $30 \% \mathrm{NE}_{\mathrm{L}}$ requirement at $\mathrm{d} 24$ (Al-Trad et al., 2009).

Fatty acid synthase is a key enzyme in the lipogenic pathway that catalyzes the terminal, rate-limiting steps involved in the de novo synthesis of FA (Laliotis et al., 2010). Fatty acid synthase represents a complex and multifunctional protein containing all the catalytic components that are required for a series of 37 sequential reactions, leading to the formation (in the presence of NADPH) of palmitic acid (Aguilar and Diegode, 2006). In all species, this enzyme is highly regulated by nutrients and hormones, including a prominent regulation by insulin via different transcription-enhancing effects (Kersten, 2001; Griffin and Sul, 2004). In sheep, starvation causes a decrease in the activity of FAS, whereas refeeding restores it (Ingle et al., 1973). When reaching the highest levels of surplus glucose supply (equating to $30 \% \mathrm{NE}_{\mathrm{L}}$ requirement) in the present study, the mRNA abundance and activity of the FAS enzyme increased to about 10 times the level of saline-infused control cows, indicating that de novo FA synthesis was enhanced in the GI group. The increase in FAS enzyme activity is consistent with previous results from Prior and Scott (1980), who observed a doubling of FAS activity after intravenously infusing $500 \mathrm{~g} / \mathrm{d}$ of glucose into steers weighing $360 \mathrm{~kg}$. The current study additionally provides evidence that the upregulation of FAS enzyme is triggered, at least to a significant part, by an increase of FAS gene transcription.

Acetate is the predominant VFA produced in the rumen by microbial fermentation (Aluwong et al., 2010; Aschenbach et al., 2011). Acetate enters the common lipogenic pathway after initial activation by ACS in the presence of CoA to acetyl-CoA, an initial substrate for lipogenesis (Knowles et al., 1974). Accordingly, ACS has been identified as a main rate-limiting enzyme involved in acetate utilization by ruminant tissues (Quraishi and Cook, 1972). Previous studies have revealed that carbohydrate feeding or infusion of glucose significantly increased the in vitro rate of acetate incorporation into FA in ovine (Ballard et al., 1972) and bovine adipose tissue (Prior and Scott, 1980). In the present study, a 5-times higher ACS activity for GI versus SI cows during the high rate $\left(30 \% \mathrm{NE}_{\mathrm{L}}\right)$ of glucose infusion was paralleled by an almost 10-times greater ACS mRNA abundance, suggesting partial regulation of ACS activity by gene transcription. Similarly to FAS, transcriptional regulation of ACS has also been ascribed to insulin, primarily, via an activation of the peroxisome proliferator-activated receptor $\gamma$ downstream the insulin signaling cascade (Kersten, 2001).

Transcriptional regulation by insulin is also prominent for ACLY. Injections of insulin into diabetic rats immediately increase hepatic ACLY mRNA and also, with a delay of $24 \mathrm{~h}$, its enzyme activity (Fukuda et al., 1992). As such, transcriptional upregulation of ACLY activity, presumably by insulin, can be extrapolated for SAT of dairy cows when combining our ACLY mRNA data with the upregulation of ACLY activity observed after glucose infusion (Prior and Scott, 1980) or highenergy feeding of steers (Schoonmaker et al. 2004). Nevertheless, the study by Prior and Scott (1980) also showed that acetate remains the most important substrate for lipogenesis after intravenous glucose infusions despite an upregulation of ACLY, which is the key enzyme for glucose carbon integration into FA.

The de novo synthesis of FA in adipose tissue requires a substantial amount of reducing equivalents in the form of NADPH for the reduction of acetyl-CoA to FA (Laliotis et al., 2010). In ruminants, around 50 to $80 \%$ of the NADPH necessary to support FA synthesis is produced by glucose oxidation via the pentose phosphate pathway (Nafikov and Beitz, 2007). Glucose 6-phosphate dehydrogenase has been identified as the main rate-limiting enzyme involved in this process (Laliotis et al., 2010). Accordingly, an increase of G6PD transcription with an increasing glucose dose may seem an appropriate measure to increase NADPH availability for lipogenesis during surplus glucose supply. An increase in G6PD mRNA abundance was, indeed, observed in the GI cows of the present study, which can most likely be ascribed to the well-established regulation of G6PD transcription by insulin (Wagle et al., 1998). However, increased G6PD mRNA transcription did not lead to higher enzyme activity, implicating that upregulation of the G6PD enzyme activity was prevented at posttranscriptional levels. This unexpected finding reflects the complex posttranscriptional regulation of G6PD enzyme activity (Stanton, 2012), and may well accommodate the metabolic needs when acknowledging (1) that huge increases in glucose supply will increase NADPH generation by G6PD despite constant G6PD enzyme activity and (2) that cattle adipose tissue alternatively enforces minor pathways of NADPH generation (NADP-malate dehydrogenase, 
NADP-isocitrate dehydrogenase) in times of increased glucose supply (Prior and Scott, 1980).

The formation of triglycerides from FA (i.e., adipogenesis) requires glycerol. The final steps of glycerol synthesis in adipocytes are controlled by G3PD, which, in turn, may also be transcriptionally upregulated by insulin upon glucose excess (Bhandari et al., 1991). The upregulation of the cytosolic G3PD-1 isoform observed in GI cows of the present study is, therefore, reflective of the increased demand for glycerol during lipogenesis in glucose-infused cows.

As elaborated above, all enzymes investigated in the present study are known to be transcriptionally regulated by insulin, and many downstream transcription factors and transcription events have been identified in rodent and cell culture models (Kersten, 2001; Griffin and Sul, 2004). By contrast, the relevance of insulin for the regulation of lipogenic enzymes in the bovine has been questioned $30 \mathrm{yr}$ ago (Smith et al., 1983). Therefore, it was a second aim of the present study to investigate whether the studied enzymes are under the control of insulin in dairy cows. Highly significant correlations between serum insulin concentrations and mRNA abundances strongly support the conclusion that all of the investigated enzymes are transcriptionally regulated by insulin in the dairy cow, too. The $\mathrm{R}^{2}$ values for the correlations varied between 0.20 and 0.42 , indicating that 20 to $42 \%$ of the variation in enzyme mRNA abundances was explainable by variation in serum insulin levels. For FAS, ACS, G3PD1, and G6PD, the regression lines had intercepts different from zero (i.e., a significant part of mRNA abundance was not related to insulin). Those intercepts were rather close to the baseline mRNA expression levels in noninfused cows, indicating that insulin regulation of these genes becomes especially relevant at elevated serum insulin concentrations. The latter may explain why it was difficult to delineate a regulatory function of insulin on lipogenic enzyme expression in a previous study (Smith et al., 1983). For ACLY, however, the regression did not possess a significant intercept, indicating that insulin is most likely an essential factor to initiate any level of transcription.

At variance to the just proposed role of insulin, the earlier study by Smith et al. (1983) came to the conclusion that glucose infusion per se, but not increased insulin availability, is responsible for an increase in lipogenic enzyme activity in bovine adipose tissue. Similarly, Kreipe et al. (2011) showed that a decrease of plasma glucose concentration by a hyperinsulinemic hypoglycemic clamp in dairy cows induces a decrease in hepatic FAS mRNA abundance despite the concurrently increased plasma insulin concentrations. This may be explained from studies in rodents and cell cultures that point to an essential role of costimulation of insulin pathways by glucose to induce the transcription of lipogenic enzymes. Costimulation by glucose possibly converges at the sterol regulatory element-binding protein (SREBP)-1c transcription factor (Foretz et al., 1999), which plays a pivotal role for insulin-mediated stimulation of FAS and other lipogenic enzymes (Griffin and Sul, 2004). In the present study, significant correlations were indeed observed between plasma glucose concentration and the mRNA abundance of all tested enzymes, as well as the activities of FAS and ACS. However, all simple regressions between plasma glucose concentrations and the significantly correlated mRNA abundances or enzyme activities possessed rather unusual negative intercepts. The latter can be most logically explained when commonly attributing them to the negative intercept of the regression between plasma glucose and serum insulin concentrations, thereby, interpreting glucose correlations as cocorrelations rather than causative correlations. This suspicion was further corroborated when fitting multiple linear regressions. In multiple linear regressions, the serum values of insulin were always better (and mostly significantly) predictive for the level of transcription of lipogenic enzymes as opposed to plasma glucose concentration. Though we fully acknowledge that glucose may be required to elicit increased transcription of lipogenic enzymes, the quantitative level of their mRNA abundance appears to be better related to the concentration of serum insulin when glucose is not limiting.

\section{CONCLUSIONS}

In conclusion, dairy cows preserved the ability to deposit any level of excess energy efficiently in adipose tissue. This was specifically verified for energy from glucose, which is usually considered a precious and limited energy source for dairy cows that rely on gluconeogenesis for glucose homeostasis. Because of the high metabolic priority for glucose production and conservation, it appeared a challenging question at which dose the metabolic switch turns adipose tissue into a main glucose metabolizing tissue. In our study, this switch operates in linear dose dependence on glucose oversupply, meaning that already moderate doses of glucose initiate a preferential deposition of the excess energy into fat. On the molecular level, this is based on linear increases in the transcription of genes involved in lipogenesis and adipogenesis, which are best predictable from the increases in serum insulin concentrations. For FAS and ACS, linearly increased gene transcription is followed by linearly increased enzyme activity. How- 
ever, an increase in enzyme activity was not observed for G6PD despite increased mRNA abundance, which may point to an increasing importance of alternative pathways of NADPH generation under such conditions.

\section{ACKNOWLEDGMENTS}

The authors thank G. Hofer, G. Mair, S. Sabitzer, A. Strasser (all at University of Veterinary Medicine, Vienna, Austria), D. Cebo (Freie Universität, Berlin, Germany), and L. Goetze (Zoetis Deutschland GmbH, Berlin, Germany) for their support. A financial contribution from Zoetis (Madison, NJ) is gratefully acknowledged.

\section{REFERENCES}

Aguilar, P. S., and M. Diegode. 2006. Control of fatty acid desaturation: A mechanism conserved from bacteria to humans. Mol. Microbiol. 62:1507-1514.

Al-Trad, B., K. Reisberg, T. Wittek, G. B. Penner, A. Alkaassem, G. Gäbel, M. Fürll, and J. R. Aschenbach. 2009. Increasing intravenous infusions of glucose improve body condition but not lactation performance in mid-lactation dairy cows. J. Dairy Sci. 92:5645-5658

Al-Trad, B., T. Wittek, G. Gäbel, M. Fürll, K. Reisberg, and J. R. Aschenbach. 2010a. Activity of hepatic but not skeletal muscle carnitine palmitoyltransferase enzyme is depressed by intravenous glucose infusions in lactating dairy cows. J. Anim. Physiol. Anim. Nutr. (Berl.) 94:685-695.

Al-Trad, B., T. Wittek, G. B. Penner, K. Reisberg, G. Gäbel, K Fürll, and J. R. Aschenbach. 2010b. Expression and activity of key hepatic gluconeogenesis enzymes in response to increasing intravenous infusions of glucose in dairy cows. J. Anim. Sci. 88:2998 3008.

Aluwong, T., I. Kobo Patricia, and A. Abdullahi. 2010. Volatile fatty acids production in ruminants and the role of monocarboxylate transporters: A review. Afr. J. Biotechnol. 9:6229-6232.

Aschenbach, J. R., N. B. Kristensen, S. S. Donkin, H. Hammon, and G. B. Penner. 2010. Gluconeogenesis in dairy cows: The secret of making sweet milk from sour dough. IUBMB Life 62:869-877.

Aschenbach, J. R., G. B. Penner, F. Stumpff, and G. Gäbel. 2011. Ruminant nutrition symposium: Role of fermentation acid absorption in the regulation of ruminal pH. J. Anim. Sci. 89:1092-1107.

Ballard, F. J., O. H. Filsell, and I. G. Jarrett. 1972. Effects of carbohydrate availability on lipogenesis in sheep. Biochem. J. 126:193200.

Bauman, D. E. 1976. Intermediary metabolism of adipose tissue. Fed. Proc. 35:2308-2313

Bhandari, B., K. S. Saini, and R. E. Miller. 1991. Glycerol 3-phosphate dehydrogenase gene expression in cultured 3T3-L1 adipocytes: Regulation by insulin, dexamethasone and dibutyryl cAMP at the level of mRNA abundance, transcription and mRNA stability. Mol. Cell. Endocrinol. 76:71-77.

Chilliard, Y., G. Gagliostro, J. Flechet, J. Lefaivre, and I. Sebastian. 1991. Duodenal rapeseed oil infusion in early and midlactation cows. 5. Milk fatty acids and adipose tissue lipogenic activities. J. Dairy Sci. 74:1844-1854.

Foretz, M., C. Pacot, I. Dugail, P. Lemarchand, C. Guichard, X. Le Lièpvre, C. Berthelier-Lubrano, B. Spiegelman, J. B. Kim, P. Ferré, and F. Foufelle. 1999. ADD1/SREBP-1c is required in the activation of hepatic lipogenic gene expression by glucose. Mol. Cell. Biol. 19:3760-3768.

Fukuda, H., A. Katsurada, and N. Iritani. 1992. Effects of nutrients and hormones on gene expression of ATP citrate-lyase in rat liver. Eur. J. Biochem. 209:217-222.
Griffin, M. J., and H. S. Sul. 2004. Insulin regulation of fatty acid synthase gene transcription: Roles of USF and SREBP-1c. IUBMB Life 56:595-600.

Ingle, D. L., D. E. Bauman, R. W. Mellenberger, and D. E. Johnson. 1973. Lipogenesis in the ruminant: Effect of fasting and refeeding on fatty acid synthesis and enzymatic activity of sheep adipose tissue. J. Nutr. 103:1479-1488.

Kersten, S. 2001. Mechanisms of nutritional and hormonal regulation of lipogenesis. EMBO Rep. 2:282-286.

Knowles, S. E., I. G. Jarrett, O. H. Filsell, and F. J. Ballard. 1974 Production and utilization of acetate in mammals. Biochem. J. 142:401-411.

Kreipe, L., M. C. Vernay, A. Oppliger, O. Wellnitz, R. M. Bruckmaier, and H. A. van Dorland. 2011. Induced hypoglycemia for 48 hours indicates differential glucose and insulin effects on liver metabolism in dairy cows. J. Dairy Sci. 94:5435-5448.

Lake, S. L., T. R. Weston, E. J. Scholljegerdes, C. M. Murrieta, B. M. Alexander, D. C. Rule, G. E. Moss, and B. W. Hess. 2007. Effects of postpartum dietary fat and body condition score at parturition on plasma, adipose tissue, and milk fatty acid composition of lactating beef cows. J. Anim. Sci. 85:717-730.

Laliotis, G. P., I. Bizelis, and E. Rogdakis. 2010. Comparative approach of the de novo fatty acid synthesis (lipogenesis) between ruminant and non ruminant mammalian species: From biochemical level to the main regulatory lipogenic genes. Curr. Genomics $11: 168-183$

Livak, K. J., and T. D. Schmittgen. 2001. Analysis of relative gene expression data using real-time quantitative PCR and the 2(-Delta Delta C(T)) method. Methods 25:402-408.

Lu, S., and M. C. Archer. 2007. Celecoxib decreases fatty acid synthase expression via down-regulation of c-Jun N-terminal kinase-1. Exp. Biol. Med. (Maywood) 232:643-653.

Luong, A., V. C. Hannah, M. S. Brown, and J. L. Goldstein. 2000. Molecular characterization of human acetyl-CoA synthetase, an enzyme regulated by sterol regulatory element-binding proteins. J. Biol. Chem. 275:26458-26466.

McLeod, K. R., R. L. Baldwin, M. B. Solomon, and R. G. Baumann. 2007. Influence of ruminal and postruminal carbohydrate infusion on visceral organ mass and adipose tissue accretion in growing beef steers. J. Anim. Sci. 85:2256-2270.

Nafikov, R. A., and D. C. Beitz. 2007. Carbohydrate and lipid metabolism in farm animals. J. Nutr. 137:702-705

NRC. 2001. Nutrient Requirements of Dairy Cattle. 7th rev. ed. Natl Acad. Sci., Washington, DC.

Pearce, J., and L. S. Piperova. 1984. The effects of duodenal glucose and dextrin infusion on adipose tissue metabolism in sheep. Comp. Biochem. Physiol. B 78:565-567.

Prior, R. L., and J. J. Jacobson. 1979. Effects of fasting and refeeding and intravenous glucose infusion on in vitro lipogenesis in bovine adipose tissue. J. Nutr. 109:1279-1284.

Prior, R. L., and R. A. Scott. 1980. Effects of intravenous infusions of glucose, lactate, propionate or acetate on the induction of lipogenesis in bovine adipose tissue. J. Nutr. 110:2011-2019.

Quraishi, S., and R. M. Cook. 1972. Utilization of volatile fatty acids in ruminants. IV. Relative activities of acetyl CoA synthetase and acetyl CoA hydrolase in mitochondria and intracellular localization of acetyl CoA synthetase. J. Agric. Food Chem. 20:91-95.

Reynolds, C. K., D. L. Harmon, and M. J. Cecava. 1994. Absorption and delivery of nutrients for milk protein synthesis by portaldrained viscera. J. Dairy Sci. 77:2787-2808.

SAS. 2002. User's Guide: Statistics. Version 9.1.3. SAS Inst. Inc. Cary, NC

Schoonmaker, J. P., F. L. Fluharty, and S. C. Loerch. 2004. Effect of source and amount of energy and rate of growth in the growing phase on adipocyte cellularity and lipogenic enzyme activity in the intramuscular and subcutaneous fat depots of Holstein steers. J. Anim. Sci. 82:137-148.

Smith, S. B., and R. L. Prior. 1986. Comparisons of lipogenesis and glucose metabolism between ovine and bovine adipose tissues. J. Nutr. 116:1279-1286. 
Smith, S. B., R. L. Prior, and H. J. Mersmann. 1983. Interrelationships between insulin and lipid metabolism in normal and alloxandiabetic cattle. J. Nutr. 113:1002-1015.

Stanton, R. C. 2012. Glucose-6-phosphate dehydrogenase, NADPH, and cell survival. IUBMB Life 64:362-369.

Vernon, R. G. 1980. Lipid metabolism in the adipose tissue of ruminant animals. Prog. Lipid Res. 19:23-106.
Wagle, A., S. Jivraj, G. L. Garlock, and S. R. Stapleton. 1998. Insulin regulation of glucose-6-phosphate dehydrogenase gene expression is rapamycin-sensitive and requires phosphatidylinositol 3-kinase. J. Biol. Chem. 273:14968-14974.

Young, J. W. 1977. Gluconeogenesis in cattle: Significance and methodology. J. Dairy Sci. 60:1-15. 